\title{
Developing Optimal Subject Representation for Adult Non-fiction Public Library Collections: The Intersections of Hermeneutics and Technology
}

\author{
Matthew Kelly, Curtin University, Australia
}

\begin{abstract}
The problem of how to select a mix of subjects for a public library collection that facilitates a holistic representation of knowledge is grounded in the question of how subjective choice can adequately suffice when a selector lacks specialised domain awareness. This paper advocates bringing hermeneutic insight to bear upon the interpretation of subject priority to create a more defined link between objectivity in knowledge organisation and the promotion of a more generalised communal understanding. The paper also outlines how knowledge domains that are considered appropriate to civil society settings can be manifested in the acts of selecting and evaluating collections and how, through bracketing these choices, a more reflexive practice might be achieved. A conceptual innovation is offered which combines the linking of a hermeneutic approach to subject knowledge with comparative meta-collection analysis, utilising the WorldCat union catalogue, to help optimise the range and depth of available information in public libraries.
\end{abstract}

Keywords: Collection Management, Hermeneutics, Public Libraries

Recommended Citation:

Kelly, Matthew. 2015. "Developing Optimal Subject Representation for Adult Non-fiction Public Library Collections: The Intersections of Hermeneutics and Technology." Journal of Technologies and Knowledge Sharing 10 (2): 11-19.

This is a revised version of a paper presented at the Tenth International Conference on Technology, Knowledge, and Society, Facultad de Ciencias de la Información, Universidad Complutense de Madrid, Madrid, Spain, 6-7 February 2014. 


\section{Introduction}

Public library collection development requires materials selectors to engage with the entire spectrum of knowledge. When we think of the spectrum of knowledge we intuitively understand that what is encompassed by such a term is a subject realm, a series of loosely connected frameworks of experience bonded by temporality and how we know. The concept is intrinsically socially dependent. While the semantic relationships between subjects receive significant treatment (as associative and hierarchical relationships) within classificatory systems as ontologies (Ingwersen and Järvelin 2005), their epistemological relationships as knowledge we need to know, in a more general sense, is largely considered as an organisational issue; the concept of the spectrum of knowledge is associated more with managing the tacit knowledge of individuals rather than as a topic for broader societal engagement. How we categorise knowledge may reflect a certain impure objectivism, but nevertheless, it is one of the primary linkages between our social worlds and the technological reality we navigate.

A lack of focus on how we choose to represent the set of subject knowledge in our public libraries has led to significant problems with dealing with this task at its epistemic roots. Questions as to what is the non-fiction collection for, what assumptions about knowledge does it represent through the range and depth of treatment of particular types of knowledge, and what might it achieve, have not been extensively researched. The alternative to approaches to information, knowledge and collections that are either sceptical-and view retrieval and relevance as the only grounding for enquiry - or user-centric and focus on an existing and preformed knowledge base, is an approach that accepts that the relationship is more subjective and dialectical in nature. It has most often been termed the domain-analytic approach (Hjørland and Albrechtsen 1995). It helps to provide the point of departure for an approach to collection development that is explicitly hermeneutic. While we do not organise documents for their own sake but for the benefit of users, the user-collection dyad can be seen as a contrast between a view of the epistemic agency of the isolated user and the epistemic practices of an integrated community. The former implies a series of preformed choices about what knowledge entails, the latter is appreciative of how transformations of knowledge can occur (Calvert-Minor 2011). Innovative uses of technology and interpretive method offer promising means for these chasms to be bridged. They promise to help facilitate a more attuned communal learning environment within the civil society information context of the public library.

Central to our problem here is an attempt to formulate the ratio that best works when evaluating a non-fiction collection for all of society. Co-operative librarianship and massive online union catalogues together create an infrastructure that offers the prospect for significant progress to be made toward assessing, understanding and selecting for library collections. The quality of public library collections would significantly benefit from increased use of the encyclopaedic and comparative functionality that applications that data mine union catalogues provide. Outlined here is an introduction to how this technology can be used within a broader framework of hermeneutically-informed collection development to supplement, rather than supplant, the choices librarians make about subject coverage.

\section{An Optimal Subject Mix}

The problem of how to select an optimal mix of subjects that provides for a holistic representation of knowledge is grounded in questions of how subjective choices can adequately suffice when selectors lack specialised domain awareness. When we attempt to create a public library non-fiction collection we are faced with several value judgements that will affect the subject topicality. Should the public library provide equal coverage to science and humanities? Should all topics within these categories be granted equal weighting? What proportion of works should be devoted to recreational and informational requirements and what to educational needs? When we look to selecting an optimal mix of subject knowledge we should look to a range of 
topics that are defined by criteria associated with the mission of public libraries: to educate, to inform and to entertain.

Since the 1970s, a self-evaluation process known as Conspectus has aimed to help libraries identify subject strengths and weaknesses primarily to aid in co-operative collection development - in effect a program for reducing duplicated collections within a given region and library type. While this process has largely fallen into desuetude for reasons that cannot be explained here, the Conspectus movement did help to place collection evaluation on a firmer footing and place subject knowledge into a more global context. A significant advance in helping practitioners understand collections emerged with the Online Computer Library Centre's creation of a collection analysis tool that allowed collections linked to its union catalogue, WorldCat, to be analysed by holdings and classification data. While libraries may have had such data within their internal systems they generally did not have the capability to efficiently analyse it and compare it to peer institutions or to the substantive database on globalised holdings that WorldCat represents. What emerged with the development of union catalogues and analysis software is the ability to move subjective professional choices in library selection and evaluation onto a more robust footing. When librarians are uninformed about the collection-level characteristics of their own collection (and that of their peers) their selection practices are largely subjective exercises in which the aim is often, simply, to match a perceived topical mix with user demands.

What emerges from comparative collection evaluation based on a domain-analytic approach is a more realistic, richer picture of what knowledge might be represented in a library collection. As Hjørland $(2013,169)$ notes "only the domain-analytic view is fully committed to exploring knowledge organisation in the light of subject knowledge and substantial scholarly theories." Through comparisons the selector is able to identify how personal preferences have impacted a collection which, ideally, should be based on well-articulated principles for representing knowledge in a holistic sense. Deploying hermeneutically-informed choice, once such an audit is carried out, helps to facilitate the common knowledge that lives at the local level and is most suitable for a civil society library collection. The nature of such choice will be outlined below.

\section{How Cognitive Approaches to Knowledge Impact Understanding of Subjectivity}

Subjective choice in information science has been most often treated as a matter for cognitive rather than interpretive inquiry. This has meant that significant epistemological matters that underpin the discipline have not been fully developed. The treatment of how subjective choice impacts information decisions has remained relatively undeveloped within the collection development specialisation. It is argued here that the cognitive focus in information science has overshadowed more interpretively focused inquiry and this has resulted in a devaluation of inquiry into domain knowledge.

The cognitive approach has an instrumental focus on messages and how their meaning inheres in the present. Meaning, as understood in interpretative contexts, looks for the received contextuality in preference to how the cognitive approach seeks an efficient mapping in "subpersonal terms" (Gallagher 2011, 12). The interstitial space between the cognitive and hermeneutic approaches has been identified as occurring at a breakdown of subjectivity in the socially induced pre-understanding that we all bring to life and its information problems (Ingwersen 1992, 41). How subjectivity is dealt with and how we prioritise individual experience, or indeed the relationship between the concept of interpretation as a "detached contemplative" endeavour, and the cognitive notion of "event-based, practice-related representations" (ibid., 48), is at the centre of the divergent approaches.

Focus on the cognitive approach tends toward a devaluation of the concept of discourse as facilitator of exchange (Budd 2005) and how "an interplay between domain structures and 
individual knowledge...interaction between the individual and the social level" (Hjørland and Albrechtsen 1995, 409) has a tendency to be relegated to the margins. As antidote, we might look to a Heideggerian framework that avows real questioning as emerging not from the common concerns of the day but from a "confrontation with subject matter;" (Heidegger 1999, 4) and engagement with interpretation, as a mode of historical explication, as a "classifying which compares forms" (ibid., 31). As a corrective project to make hermeneutics "fix" epistemology and by placing the task of "making sense of things" at the very centre of philosophy, interpretation can be made to go beyond text and enter an ontological space for "a being that understands itself in time, and whose own being is concerned with being" (Grondin 1994, 20). Interpretation is the method through which we can gain understanding of how information systems promote epistemically valuable beliefs and how information services are able to facilitate knowledge acquisition (Fallis 2006).

\section{Hermeneutic Methods Help to Bridge Problems of Objectivity}

Outlined here is an approach that involves bringing hermeneutic insight to the interpretation of subject priority for public libraries in order to reconcile the perceived need for objectivity in information organisation with the educational role of communicating, and promoting, understanding. While some responses to information overload have been to advocate managing the information on offer all the while scaling back subject coverage (Qvortrup 2007), the approach advocated here differs. While agreeing with Qvortrup that more management of information is needed, this strategy advocates returning to categorisation and classification as the starting point in helping users of collections navigate the oceans of knowledge on offer. Selecting not into the broadest domains of 10 or 20 categories but to evaluate coverage across say 500 subjects should be the normative ideal.

As public libraries do not normally collect to retain, the depth of materials should not be a priority. Treating materials in depth hampers the ability to provide subject coverage due to limitations on resources. Satisfying some part of most information needs is substituted as a worthwhile goal for the lack of depth. Selecting materials from across a wide spectrum of subject areas is a straightforward approach to ensuring that a collection is balanced and does not unduly reflect the predilections of the selector. The hermeneutic insight of the selector is called upon to prioritise these factors and to instantiate them into the collection at the level of the title.

In our collection focus on subject we are dealing with the interpretation of forms and how they are built up over time. One instantiation of this is perspective hierarchy or "the syntagmatic relationships embodied in classificatory tree structures" - which do not act as scientific referents but rather "indicate a point of view or method of treatment" (Svenonius 2004, 583). Another is the indexicality within scientific work. Like collections, which are often built up using simple criteria, the indexicality of science largely sees growth in knowledge emerge from the simplicity of "relatively short term concerns of exclusively local relevance" (Knorr-Cetina, 1981, 37).

By trying to understand what matters and allowing that such questions are not standardised scientific questions, but more detailed representations of the composition of materials, the quantification of coverage and control of complexity and comparability, these interpretative variables allow for a more perfect setting of criteria for creation of a shared ontology of significance. A process of evaluating what matters ought to acknowledge how, as Longino has explained, "value neutrality places unrealistic constraints on science" (Longino 1990, 131). As a procedural ground, we may treat science as we do the formation of collections: both are valueladen. Despite this, we should acknowledge that value-free science or value-free subject choice (even as unachievable goals), may still perform a mediatory role helping to sharpen the focus on evidential, rational and objectively-oriented knowledge. Integral to this is "treating scientific knowledge as social knowledge" (ibid, 15) and the derivative epistemological claims that emerge from it as existing within a cultural context of needs and values. 


\section{Bracketing Domain Preferences}

The approach advocated here aims to reveal how knowledge domains that are considered appropriate to civil society settings are manifested in the acts of selecting and evaluating collections and how bracketing these choices promotes reflexive practice. In line with this, a personal bracketing of preferences is offered by way of example.

It is proposed here that we should not see as inconsistent with a humanistic program for civil society collections that a prioritisation of scientific literacy is explicitly advanced, as is the promotion of a realistic and objective approach to knowledge. Such a program demands, however, that a relatively shallow treatment of science, due to its vast complexity, is accepted as normative within the context of the civil society library. This should be balanced by a commitment to a pan-optical representation of scientific disciplinary knowledge. What we do not treat as science we can group as expressions of humanitas and techne, or much adumbrated, literary-philosophical inquiry and practical fields of knowledge. This is, in effect, our collection in toto-bracketed at a high-order domain level. We can, and should, continue to unravel the layering. What are we left with?

As cultural affordances (Day 2010, 178) operating with reference to their social and historical situation, it is possible to blur the distinction between humanitas and techne so that their differences are put aside, momentarily, to allow their expression as art constituting an "authentic collective existence" (Elliott 2005, 124). A more prosaic view requires that we continue to try to delineate their relative prioritisation. Taking a cue from Heidegger, we can ask how "classifying which compares forms" (Heidegger ibid, 31), making sense of things, or simply, practical wisdom, might "occur against a background of a community that develops over time and articulates itself linguistically" (Grondin ibid, 31).

While the practical arts are inseparable from broader notions of cultivation, for a civil society library they do not, as cultural affordances, provide the same warrant as matters that deal with issues of truth, cultural memory and the qualities of being human. These themes then become the central focus of a civil society library collection and significant priority should be allocated to develop the humanitas collection. The strong program for humanitas collection priority defined here would ordinarily necessitate a diminution of resources for the materials associated with practical arts. But an important caveat remains: the principle of extensive subject coverage should guide selection before subsidiary considerations of topicality.

\section{How Bracketing Subjective Choice Can Help Develop Civil Society's Knowledge Base}

Bracketing is one of a number of methods within the tradition of phenomenological hermeneutics that offer promise for interpreting subject priority; its advocacy here is based upon how it allows for particularly sharp focus to be made on the ways personal preference becomes an affective force on a collection. In order that collections do not end up reflecting simply the familiar and the mundane, selectors should look to how their personal predilections may impact upon subject coverage. While bracketing our preconceived understanding of the world is acknowledged as not entirely unproblematic, following this path can help to ensure that the relative treatment of science, humanitas and techne might be balanced in public library collections. Inspiration for this can be found in Heidegger's early work on facticity which is touched on later.

Vamanu points to how "understanding does not amount to a disinterested act of reconstruction of the meaning intended by its author, but rather to a process of coming to an agreement on the subject matter" (2013, Understanding and prejudgements). When we consider facticity and knowledge priority, we engage with the nature of our own prejudgement. If we find our projections unfulfilled, we experience a "break in our understanding," which may require us to suspend our assumptions in order to attempt a renewed understanding of the topic under consideration, possibly through a process of deeper research (ibid, The circle of understanding). 
Just as this method is oriented at engaging particular texts, its principles are consistent with broader information problems such as those associated with subject selection. We need to bracket our own assumptions about topical relevance in order to allow ourselves the freedom to reincorporate them afresh if they are still warrantable when looked at with our prejudices (or assumptions) revealed.

\section{The Meeting of Minds through Technology to Better Understand Subject and Domain}

The approach developed here interfaces with comparative meta-collection analysis utilising union cataloguing and looks to methods by which not only the domain representations, but the range and depth of available information within domains, can be optimised through combining such analysis with bibliometric methods. In recent decades libraries have been looking at ways to understand their collections with reference to their peers and not just to bibliographies drawn up by subject specialists. One of the more innovative approaches was developed by White (1995) who looked at title popularity as a measure of difficulty of holding a work and whether it could be justified being acquired in a particular library - and how this interfaced with cumulative levels of holdings (essentially that there is a strong probability that research libraries also hold introductory titles). White used a bibliographic list drawn up by a specialist to compare libraries' holding counts. In later work White (2008) brought a new approach where an entire subject literature held in a library was compared against the holdings in a union catalogue (WorldCat). Seeking to elicit coverage power, through identifying how a collection fits with the often exhaustive title list (in excess of 300 million titles in 2013) of the union catalogue, and with reference to Conspectus categories (essentially levels of holdings from Basic through to Research), White's aim was to understand how well sophisticated collections performed against such a matrix. As an evidence-based evaluation measure it allows for a far greater level of certainty and comparability than had been available previously. In a collaboration between White and a group of Australian researchers these concepts were taken into a bibliometric realm that aimed to evince how holdings counts in union catalogues can shed new light on the cultural impact of humanities and social science monographs which are often missed in citation analyses that focus on natural science journals (White et al 2009). The argument made is that committing resources to acquiring a book is, in effect, a librarian's citation or a "bibliographic speech act" and is significant in and of itself (ibid, 1094).

The Online Computer Library Centre supports an application for member libraries that enables comparison to be made of their collections with a set of peer libraries so that information about relative proportions of literatures can be defined. The ability to define collection holdings using a detailed subject listing, and so to define gaps and allow remedial selection to take place, is of great benefit to promoting scientific selection practices. Knowledge of how powerful collections are at representing subjects is also conversely the power to make valid decisions about where, and how deeply, to deliberatively focus resources to enhance the potential to meet a community's needs.

This knowledge contributes to a vast capability to know what we know and what our collection can inspire in its users. It allows us to create a worthwhile core to our collections that provides the freedom to acquire new and exciting works that we would, perhaps, not have selected for fear of the works being regarded as too abstruse. Likewise, it allows us to reflect on why our civil society collections have materials for all users, not just the scholarly-bytemperament: we can afford all types of works in our collections because we have repaired the walls of subjectivity and strengthened the gates of knowledge. 


\section{Conclusion}

When we look to developing optimal subject representation throughout a civil society collection we are, first and foremost, looking at what broad domains simply require some representation and what domains deeper representation. It seems quite unremarkable to assert that, with limited resources, complex subjects such as those within scientific domains can only be dealt with tangentially. But it needs to be said that they must be dealt with extensively, if not deeply, in order to fulfil the educational mission of the public library. Despite this entreaty, science is not the heart and soul of civil society collections, and while human sciences are rightly represented, they do not as a rule exemplify the human condition but are taxonomies of it.

Claims that the information needs of users differ across cities or nations in their civil society contexts is to miss the point that relevant collections-with selection based on broadly hermeneutic principles - will often have much in common. Both Suominen $(2007 ; 2008)$ and Hjørland $(1992 ; 2002)$ have variously explained the user focus that this interdicts with. Suominen $(2008,175)$ points to how "criticism of the Cartesian subject within LID [Library studies, Information and Documentation] is actually missing the point in the sense that it seems not to recognise the specific philosophical perspective, within which the whole Cartesian epistemology should be considered. This may also be seen as a consequence of the fact that the criticism is based on a somewhat shallow reconstruction of Descartes' writings." Hjørland's early criticism includes taking aim at "those researchers who place...subjects in the minds of the users (and) have a conception of 'subject' different to that possessed by those who regard the subject as a fixed property of the documents" $(1992,172)$. Heidegger's early engagement with hermeneutics advanced the view that we ought not focus on it as a broad doctrine of interpretation but as an actualisation of communication or an interpreting of facticity. From such contretemps we may, in fact, make an advance in how we incorporate hermeneutics into collection evaluation; looking less at the problems of the times (as important as they are), our focus should be to deal directly with how "questions grow out of a confrontation with 'subject matter' " (Heidegger, ibid, 4).

By interpreting what matters for civil society libraries in light of a limited temporality - one that is attuned to the historically-situated nature of our shared being-and maximising the benefits of technology (such as union catalogues) to help constitute, in the words of Heidegger, "the open space of publicness" and "that averageness in which each can easily follow along, be involved, and be at home," (ibid, 26) it is now becoming exceedingly possible for all public libraries to optimise subject representation in their collection.

The subject knowledge whose facticity is contextualised by such an approach is then, in a sense, opened up to a more reasonable expression of subjective choice. Hermeneutic methods allow us to navigate the space between the subjective and objective choices associated with significance with a renewed focus on both the users and the knowledge traditions with which we are dealing.

\section{Reference List}

Budd, John, M. 2005. "Phenomenology and Information Studies." Journal of Documentation 61 (1): 44-59.

Calvert-Minor, Chris. 2011. "Epistemological Communities' and the Problem of Epistemic Agency." Social Epistemology 25 (4): 341-360.

Day, Ronald. 2010. "Martin Heidegger's Critique of Informational Modernity." In Critical Theory for Library and Information Science: Exploring the Social From Across the Disciplines, edited by Gloria J. Leckie, Lisa M. Given, and John E. Buschman, 173-188. Libraries Unlimited: Santa Barbara.

Elliott, Brian. 2005. Phenomenology and Imagination in Husserl and Heidegger. London and New York: Routledge. 
Fallis, Don. 2006. "Social Epistemology and Information Science." Annual Review of Information Science and Technology 40 (1): 475-519.

Gallagher, Shaun. 2011. "Hermeneutics and the Cognitive Sciences." Journal of Consciousness Studies 11 (10-11): 162-174.

Grondin, Jean. 1994. Introduction to Philosophical Hermeneutics. Translated by Joel Weinsheimer. New Haven: Yale University Press.

Heidegger, Martin. 1999. Ontology-The Hermeneutics of Facticity. Translated by John van Buren. Indianapolis: Indiana University Press.

Hjørland, Birger. 1992. "The Concept of 'Subject' in Information Science." Journal of Documentation 48 (2): 172-200.

2002. "Domain Analysis in Information Science: Eleven Approaches-Traditional as well as Innovative." Journal of Documentation 58 (4): 422-462.

2013. "Theories of Knowledge Organisation-Theories of Knowledge." Knowledge Organisation 40 (3): 169-181.

Hjørland, Birger and Hanne Albrechtsen.1995. "Toward a New Horizon in Information Science: Domain-Analysis." Journal of the American Society for Information Science 46 (6): 400-425.

Ingwersen, Peter. 1992. Information Retrieval Interaction. London: Taylor Graham.

Ingwersen, Peter and Kalervo Järvelin. 2005. The Turn: Integration of Information Seeking and Retrieval in Context. Dordrecht: Springer Netherlands.

Knorr-Cetina, Karen. 1981. The Manufacture of Knowledge: An Essay on the Constructivist and Contextual Nature of Science. Oxford: Pergamon Press.

Longino, Helena. 1990. Science as Social Knowledge: Values and Objectivity in Scientific Inquiry. Princeton: Princeton University Press.

Qvortrup, Lars. 2007. "The Public Library: From Information Access to Knowledge Management: A Theory of Knowledge and Knowledge Categories." Information Research, 12 (4). www.informationr.net/ir/12-4/colis17.html.

Suominen, Vesa. 2007. "The Problem of 'Userism', and How to Overcome it in Library Theory." Information Research 12 (4). http://www.informationr.net/ir/12-4/colis/colis33.html 2008. "Social Constructionism, Hermeneutics, Conceiving of the User and Use, and the Issue of the Cartesian Subject." In From Information Provision to Knowledge Production. Proceedings of the International Conference for the Celebration of the 20th Anniversary of Information Studies, Faculty of Humanities, University of Oulu, Finland, June 23-25, edited by Maija-Leena Huotari and Elisabeth Davenport, 175-192. Oulu: University of Oulu.

Svenonius, Elaine. 2004. "The Epistemological Foundations of Knowledge Representations." Library Trends 52 (3): 571-587.

Vamanu, Iulian. 2013. "Hermeneutics: A Sketch of a Metatheoretical Framework for Library and Information Science Research.” Information Research 18 (3) http://www.informationr.net/ir/18-3/colis/paperS08.html\#.U_yYKtR-_jo

White, Howard D. 1995. Brief Tests of Collection Strength: A Methodology for All Types of Libraries. Westport CT: Greenwood Press.

2008. "Better Than Brief Tests: Coverage Power Tests of Collection Strength." College and Research Libraries 69 (2): 155-174.

White, Howard D., Sebastian K. Boell, Hairong Yu, Mari Davis, Concepción S. Wilson and Fletcher T. H. Cole. 2009. "Libcitations: A Measure for Comparative Assessment of Book Publications in the Humanities and Social Sciences." Journal of the American Society for Information Science and Technology 60 (6): 1083-1096. 